\title{
Effects of uniform field flicker on type 1 and type 2 visible persistence
}

\author{
GERALD M. LONG and JOYCE L. HOMOLKA \\ Villanova University, Villanova, Pennsylvania
}

\begin{abstract}
The effect of uniform field flicker (UFF) on two estimates of visible persistence was determined for brief presentations of foveal and parafoveal letter arrays. Type 1 persistence (offset perception) exhibited an inverse relationship with target luminance; type 2 persistence (end-of-trace perception) exhibited a positive relationship with target luminance. However, these luminance effects were clearly moderated by UFF. Implications for likely differences across studies in the persistence literature and for underlying mechanisms are discussed.
\end{abstract}

In the last dozen years, there has been a growing acceptance of the proposal that more than a single type of persistence may exist in the visual system. On the one hand, several researchers have argued for a necessary distinction between visible and nonvisible persistence (e.g., Coltheart, 1980; DiLollo \& Dixon, 1988). In such a conceptualization, some information from a brief target may be available to the observer but not from a phenomenally fading visual image in the manner favored by the early researchers in iconic memory. This kind of persistence would not be susceptible, for example, to masking effects, which effectively eliminate the fading visible image (e.g., Averbach \& Coriell, 1961; Irwin \& Brown, 1987). On the other hand, several researchers have proposed that even visible persistence may not reflect a single process or phenomenal experience (e.g., DiLollo, Clark, \& Hogben, 1988; Hawkins \& Shulman, 1979; Long, 1979, 1985a). Within this latter proposal, different popular persistence tasks have been hypothesized to tap different "types" of visible persistence. Type 1 persistence has been attributed to those tasks that characteristically involve considerable target flicker or motion or that require the observers' attending to target offset; type 2 persistence has been attributed to those tasks that involve single presentations of a brief target and assess the observers' reports of any lingering trace of the brief target. Nisly and Wasserman (1989) have recently reviewed much of the evidence in support of this distinction between type 1 and type 2 persistence.

The present study sought to demonstrate the value of this distinction between type 1 and type 2 visible persistence by assessing the effect of a single powerful manipulation on both types of persistence under otherwise identical stimulus conditions. It was hypothesized that the different

\footnotetext{
The data contained in this article were presented at the 1990 Annual Meeting of the Psychonomic Society in New Orleans. Address correspondence to Gerald M. Long, Department of Psychology, Villanova University, Villanova, PA 19085.
}

processes underlying the two types of persistence might exhibit markedly different sensitivities to the same experimental treatment. The particular manipulation chosen for this work was that of uniform field flicker (UFF). Previous investigators (e.g., Breitmeyer, Levi, \& Harwerth, 1981; Slaghuis \& Lovegrove, 1984) have employed uniformly flickering backgrounds in persistence tasks (as well as in other visual tasks) as a means by which to separate transient (magno?) and sustained (parvo?) channel activity in such tasks. The flickering background is believed to engage the transient channels very strongly because of the special affinity of these channels for visual onsets and offsets (Green, 1984). As a result, processing of a target that is superimposed on this background is believed to be largely handled by the more sluggish sustained channels, which are relatively insensitive to a flickering field. Consistent with this hypothesis, these previous studies have reported that the effect of UFF is to increase estimates of visual persistence in a manner indicative of greater sustained channel mediation.

If the two types of visible persistence described above are differentially dependent on the transient and sustained channels, then UFF may exhibit very different effects on those tasks that assess the two types of persistence. The studies cited above that examined the effect of UFF on persistence estimates used persistence tasks in which a target was cycled with progressively longer blank intervals until the target no longer appeared continuous. This "persistence-of-form" task, which exhibits an inverse relationship with both target luminance and spatial frequency, has been proposed to involve only type 1 persistence (cf. Long, 1985a). The present work sought to extend the UFF procedure to other common persistence tasks. Following Nisly and Wasserman's recent review (1989), a common persistence task that involves offset judgments was chosen as a representative type 1 persistence task. In addition, another common task that required the observer to report the total lingering trace of a brief target was chosen as a representative type 2 persistence task. Both of these tasks were performed against either a steady or a flickering background of the same average luminance. 


\section{METHOD}

\section{Subjects}

Under each of the four experimental conditions defined by the crossing of two persistence tasks and two retinal locations, 2 subjects were run in six to eight 40-min experimental sessions following a 30-min practice session. Subjects were either graduate student volunteers who were paid for their participation or one of the authors. At least one of the subjects in each condition was naive with respect to any experimental hypotheses. All subjects exhibited a minimum acuity of 20/20 (either natural or corrected).

\section{Apparatus and Stimuli}

A modified projection tachistoscope with two six-channel Gerbrands timers (Model G1177), four Gerbrands millisecond shutters, and four Kodak Ektagraphic projectors (Model AF-1) was used to present all target and background conditions on an opal glass screen that was rear viewed by the observer. In all cases, target stimuli consisted of a $2 \times 2$ array of white letters (randomly selected consonants) centered around a fixation cross. In the foveal conditions, the overall letter array subtended $1^{\circ}$ of visual angle in height and width, with each individual letter subtending approximately $0.3^{\circ}$ in height. The subject viewed the array from a distance of $2.5 \mathrm{~m}$, and the background field on which the target array was presented subtended $8.5^{\circ} \times 9.1^{\circ}$ at this viewing distance. A small $\left(0.2^{\circ}\right)$ probe was located $5^{\circ}$ to the right of the fixation point against a constant black background.

In the parafoveal conditions, each target letter in the array subtended $1.4^{\circ}$ in height and the overall letter array subtended $6.5^{\circ}$ in height and width. For these conditions, the subject was seated $1.0 \mathrm{~m}$ from the display, which subtended $21.1^{\circ} \times 22.9^{\circ}$ at this viewing distance, and the small probe was located $12.5^{\circ}$ from the fixation point.

In the steady background condition for each of the two letter arrays, the white background was a constant luminance of $3.4 \mathrm{~cd} / \mathrm{m}^{2}$. In the uniform-field-flicker background condition, the entire background flickered at a rate of $4 \mathrm{~Hz}$. The time-averaged background luminance was again $3.4 \mathrm{~cd} / \mathrm{m}^{2}$ (identical to the steady background), but the luminance varied by $20 \%$ around this average value. (Badcock \& Smith, 1989, have reported this degree of contrast modulation to be quite effective in engaging the transient channels.) Against these two background conditions, the letter array was presented for $50 \mathrm{msec}$ at either of two luminance levels, 0.5 and $5.0 \mathrm{~cd} / \mathrm{m}^{2}$. Target luminance was controlled by placing appropriate Kodak Wratten No. 96 filters in front of the lens of the target projector. In the manner described below, a 20-msec probe of a constant luminance $\left(3.4 \mathrm{~cd} / \mathrm{m}^{2}\right)$ was presented at a variable interstimulus interval (ISI) after offset of the letter array.

\section{Procedure}

Subjects in the type 1 persistence condition were administered an "offset-judgment" task that has been used in several published studies in the persistence literature (e.g., Bowen, Pola, \& Matin, 1974; Efron, 1970; Long \& Gildea, 1981). Specifically, subjects were instructed to attend to the offset of the letter array. In a double-staircase procedure, the ISI between target offset and probe onset was varied in 20-msec steps, and the observer reported after each presentation whether the probe was "early" or "late" with respect to target offset. The ascending or descending run for a given target condition was terminated after the observer made four response reversals. Under each combination of conditions (foveal vs. parafoveal letters and low vs. high luminance), estimates of persistence were obtained from 18 pairs of ascending and descending runs for each observer over several sessions. Within each session the order of the ascending and descending runs as well as the order of the two target luminances was randomized for each observer.

Subjects in the type 2 persistence condition (regardless of foveal or parafoveal location of target array) were instructed to attend to any lingering image of the brief target array. Again, a double-staircase procedure was used to vary the latency for the probe (ISI) in 20-msec steps in order to determine the phenomenal duration of this visible persistence from the brief letter arrays. In all other respects, the conditions were identical to those described above for the assessment of type 1 persistence. This end-of-persistence task has also been used in several published articles in the persistence literature (e.g., Long, 1985b; Long \& McCarthy, 1982; Long \& Sakitt, 1981).

\section{RESULTS AND DISCUSSION}

Figures 1 and 2 present the mean persistence estimates obtained under the type 1 persistence instructions with the foveal and parafoveal target arrays, respectively. In both figures, a strong inverse luminance effect is clearly evident; this replicates the findings of previous studies with this kind of persistence task (see Nisly \& Wasserman, 1989). In addition, for both display sizes the effect of UFF is to increase significantly the persistence estimates of the observers. This, too, is consistent with previous resultsalthough to our knowledge this effect has not been reported with this particular persistence task or with letters as targets. Such a similarity of results across different tasks adds strong support to the claim that the persistence-ofform procedure used in the earlier work (e.g., Breitmeyer et al., 1981) and the offset-judgment procedure of the present work are assessing the same kind of visible persistence (see Long, 1985a, and Nisly \& Wasserman, 1989, for a discussion of the issue of task comparability in the persistence literature). Moreover, the positive effect of UFF suggests the important role of the transient channels on this type of persistence, as argued by Breitmeyer et al. (1981).

Figures 3 and 4 present the analogous results for the type 2 persistence instructions under the foveal and parafoveal target conditions, respectively. These results contrast with those for the type 1 instructions on several

TYPE 1 PERSISTENCE
(FOVEAL)

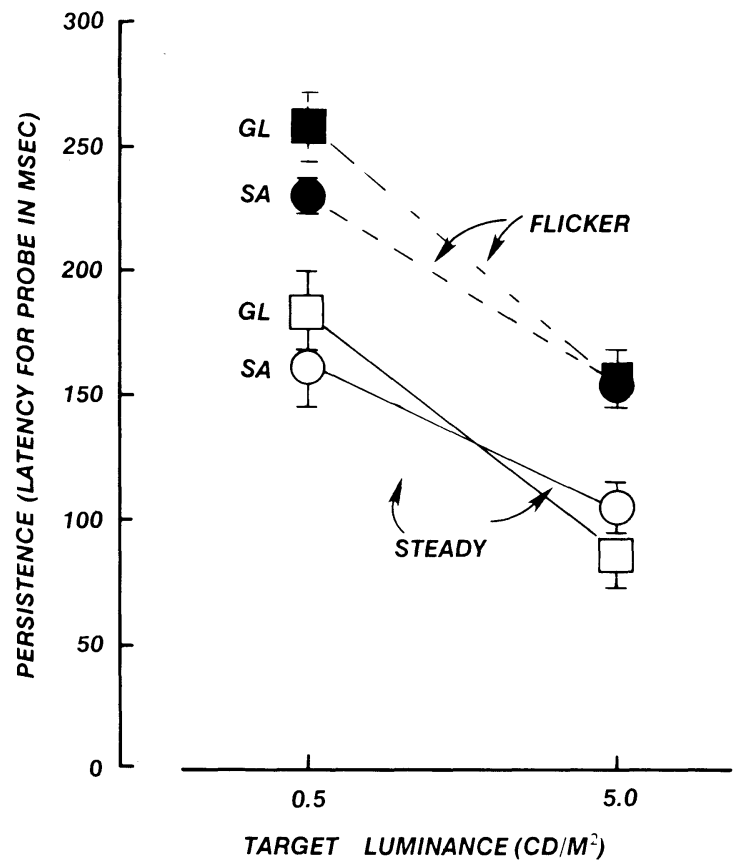

Figure 1. Mean visible persistence estimates on the offset-judgment task (type 1 persistence) for the two levels of foveal target luminance with both steady and flickering backgrounds. The brackets around each mean represent the standard error for that point. 


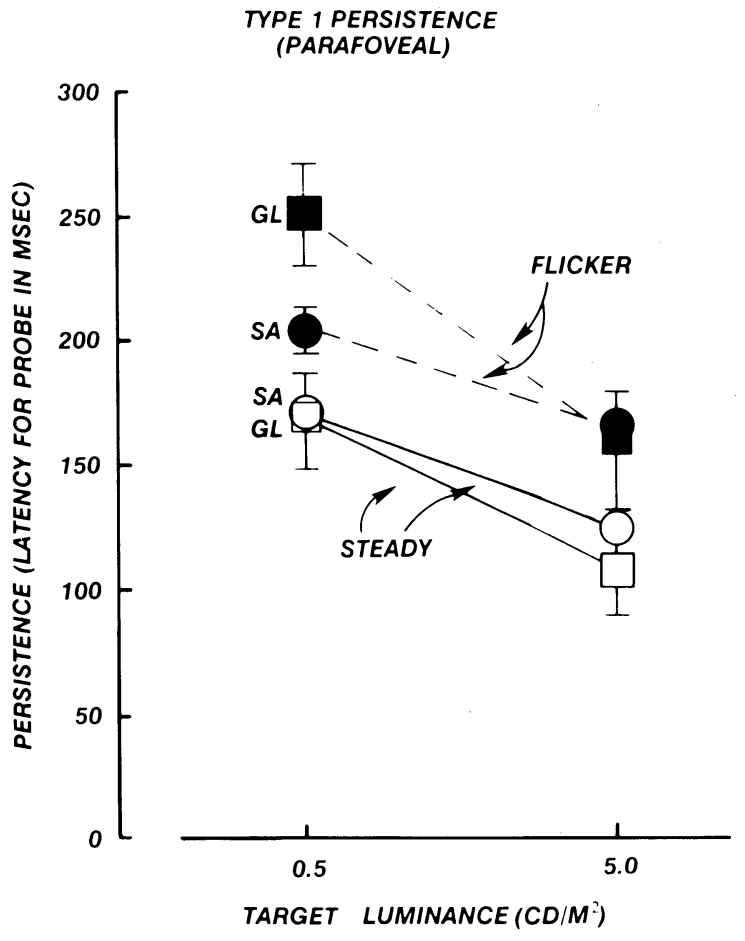

Figure 2. Mean visible persistence estimates on the ofiset-judgment task (type 1 persistence) for the two levels of parafoveal target luminance with both steady and nickering backgrounds. The brackets around each mean represent the standard error for that point.

dimensions. First, the absolute level of the persistence values is very different, with the type 2 estimates attaining average values up to several hundred milliseconds longer than did the type 1 estimates under the identical stimulus conditions. This replicates the findings of earlier work (e.g., Long \& McCarthy, 1982) concerning the very different durations of the visible persistences assessed by type 1 and type 2 tasks. Second, the inverse luminance effect evident in the previous two figures is completely absent in Figures 3 and 4 . Under the steady background condition that has traditionally been employed in persistence work, a positive effect of increasing target luminance is present. This is consistent with previous reports in the literature for type 2 tasks (cf. Nisly \& Wasserman, 1989). However, under the UFF condition in the present work, there is no evidence for any effect of increasing target luminance on the type 2 persistence estimates for either observer with either target location. Finally, while UFF seems to have a generally positive effect on the persistence estimates, this effect is only reliably present at the low target luminance. ${ }^{1}$

The extension of UFF to type 2 persistence tasks has produced some interesting differences from the results of previous work that has been restricted to type 1 persistence tasks. While UFF exhibits a_generally additive effect on type 1 persistence in the conditions employed in this work, its effect on type 2 persistence is more complex. UFF generally increases type 2 estimates, but it also attenuates the expected increase in persistence as target luminance was increased. That is, the positive effect of increasing target luminance that has been reported for type 2 persistence tasks is absent when a flickering background is used. These empirical differences between the two kinds of persistence estimates cannot be attributed to the use of widely differing stimulus conditions, which has often been argued. Rather, such a finding is consistent with the claim that different processes underlie the visible persistences revealed by the two types of persistence tasks.

At the present time, we are unable to specify the precise relationships between transient (magno?) and sustained (parvo?) channels in the several conditions employed in this work. While the generally positive effect of flicker (on both types of tasks) is consistent with greater sustained channel activity (and therefore slower neural processing), the reason for the interaction between flicker and luminance on the type 2 persistence task is not immediately evident. Research continues in an effort to elucidate this finding. And finally, the strong interaction between stimulus variables evident in this work further emphasizes the care that must be exercised by researchers concerning conclusions about the nature of visual persistence that can be drawn from results obtained with a sin-

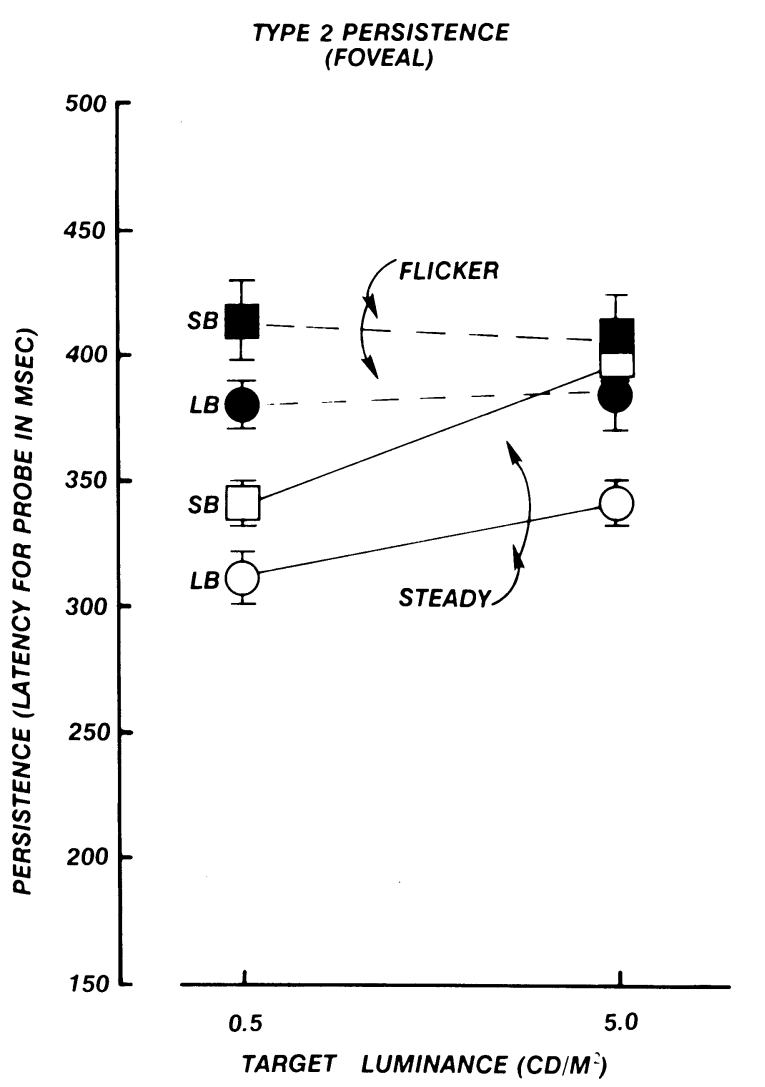

Figure 3. Mean visible persistence estimates on the end-of-trace task (type 2 persistence) for the two levels of foveal target luminance with both steady and fickering backgrounds. The brackets around each mean represent the standard error for that point. 


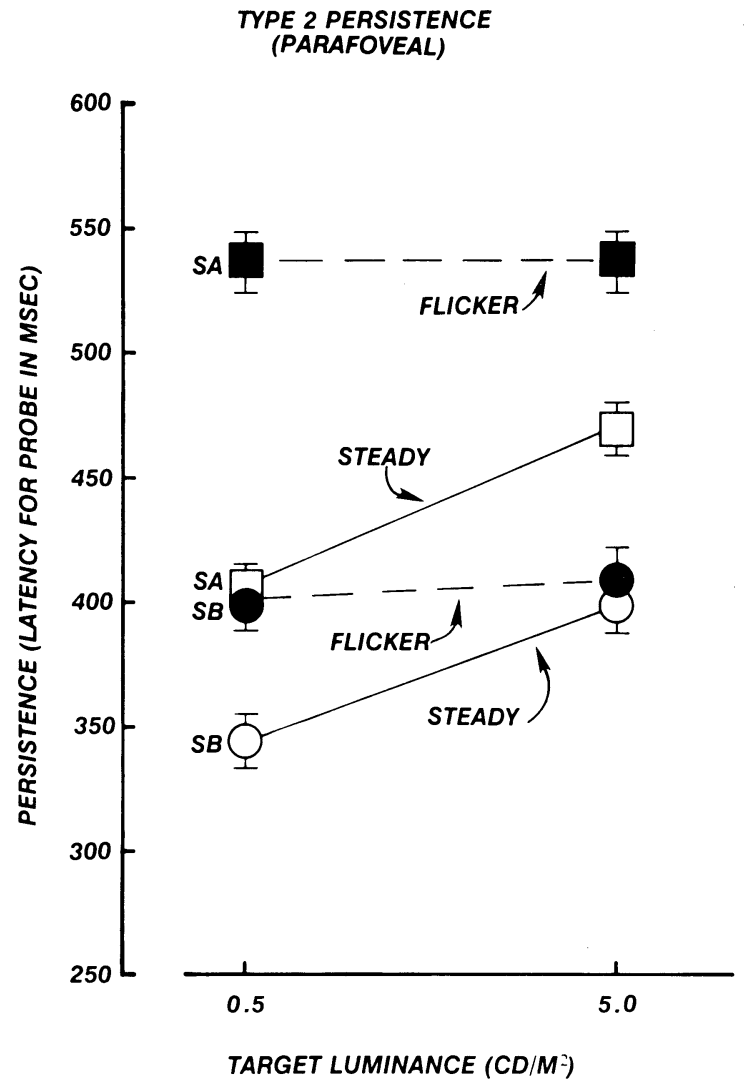

Figure 4. Mean visible persistence estimates on the end-of-trace task (type 2 persistence) for the two levels of parafoveal target luminance with both steady and fickering backgrounds. The brackets around each mean represent the standard error for that point.

gle type of persistence task and a limited set of stimulus conditions.

\section{REFERENCES}

Averbach, E., \& Coriell, E. (1961). Short-term memory in vision. Bell System Technical Journal, 40, 309-328.

BADCOCK, D. R., \& SMITH, D. (1989). Uniform field flicker: Masking and facilitation. Vision Research, 29, 803-808.
Bowen, R. W., PolA, J., MAtin, L. (1974). Visual persistence: Effects of flash luminance, duration, and energy. Vision Research, 14, 295-303.

Breitmeyer, B., Levi, D. M., \& HarWerth, R. S. (1981). Flicker masking in spatial vision. Vision Research, 21, 1377-1385.

Coltheart, M. (1980). Iconic memory and visible persistence. Perception \& Psychophysics, 27, 183-228.

Dilollo, V., ClARK, C. D., \& HogBEN, J. H. (1988). Separating visible persistence from retinal afterimages. Perception \& Psychophysics, 44, 363-368.

DiLollo, V., \& Dixon, P. (1988). Two forms of persistence in visual information processing. Journal of Experimental Psychology: Human Perception \& Performance, 14, 671-681.

EFron, R. (1970). Effect of stimulus duration on perceptual onset and offset latencies. Perception \& Psychophysics, 8, 231-234.

GreEN, M. (1984). Masking by light and the sustained-transient dichotomy. Perception \& Psychophysics, 35, 519-535.

HawkINS, H. L., \&hulman, G. L. (1979). Two definitions of persistence in visual perception. Perception \& Psychophysics, 25, 348-350.

IrWIN, D. E., \& BrowN, J. S. (1987). Tests of a model of informational persistence. Canadian Journal of Psychology, 41, 317-338.

LoNG, G. M. (1979). Comment on Hawkins and Shulman's Type I and Type II visual persistence. Perception \& Psychophysics, 26, 412-414.

LoNG, G. M. (1985a). The varieties of visual persistence: Comments on Yeomans and Irwin. Perception \& Psychophysics, 38, 381-385.

LoNG, G. M. (1985b). Visual persistence from brief letters and pictures. Vision Research, 25, 887-892.

LoNG, G. M., \& GILDEA, T. J. (1981). Latency for the perceived offset of brief target gratings. Vision Research, 21, 1395-1399.

LONG, G. M., MCCARTHY, P. R. (1982). Target energy effects on Type I and Type II visual persistence. Bulletin of the Psychonomic Society, 19, 219-221.

LoNG, G. M., \& SAKrTT, B. (1981). Differences between flicker and non-flicker persistence tasks: The effects of luminance and the number of cycles in a grating target. Vision Research, 21, 1387-1393.

Nisly, S. J., \& WAsserman, G. S. (1989). Intensity dependence of perceived duration: Data, theories, and neural integration. Psychological Bulletin, 106, 483-496.

SLAGHUTS, W. L., \& LOVEGROVE, W. (1984). Flicker masking of spatialfrequency-dependent visible persistence and specific reading disability. Perception, 13, 527-534.

\section{NOTE}

1. The same pattern of results for type 2 persistence was reported by Laura Pasquale in an unpublished master's thesis, Villanova University, 1989.

(Manuscript received July 15, 1991.) 